\title{
Synthesis and kinetic studies of mutual azo prodrugs of -aminosalicylic acid with sulfamethoxazole and trimethoprim as models for colon targeting
}

\author{
Yasser Fakri Mustafa \\ Department of Pharmaceutical Sciences, College of Pharmacy, \\ University of Mosul, Iraq.

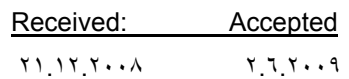

\begin{abstract}
In this study, two mutual azo prodrugs were synthesized for colon targeting in a treatment of colonic diverticular disease. The first was synthesized by coupling sulfamethoxazole with salicylic acid; the second was synthesized by coupling one mole of trimethoprim with two moles of salicylic acid. In vitro kinetic studies of these mutual prodrugs in hydrochloric acid buffer $(\mathrm{pH}, . r)$ and in phosphate buffer $(\mathrm{pH} \vee . \varepsilon)$ were monitored. Hydrolysis of these mutual prodrugs was established in rat fecal matter. The release of $\bullet$-aminosalicylic acid and sulfamethoxazole or trimethoprim from these mutual prodrugs was almost complete and it followed first order kinetics. The prodrug approach to drug physicochemical properties modification based on enzyme specifications may offer a new approach for improving drug product efficacy and reducing most of its adverse effects.
\end{abstract}

الخلاصة

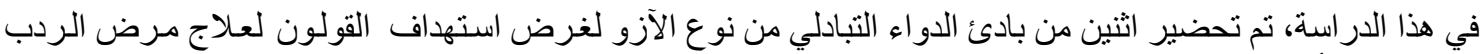

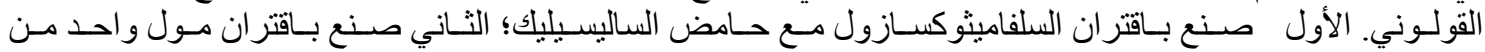

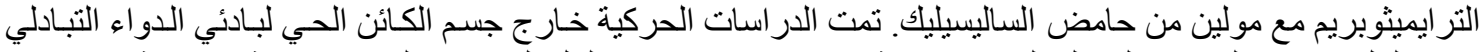

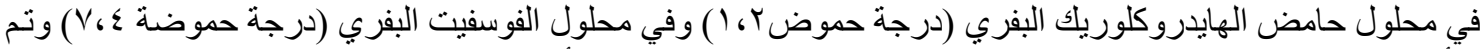

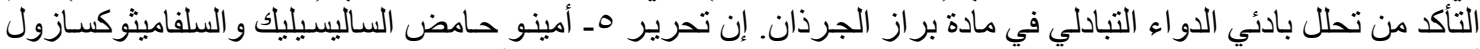

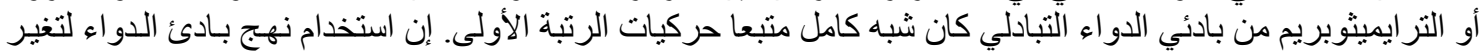

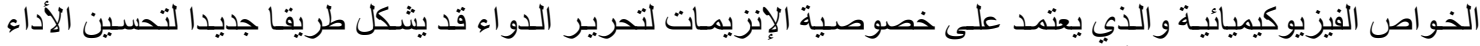
العلاجي للاو اء وتقليل معظم أثاره الجانبية.

$\mathrm{D}$ iverticulitis of colon is quite frequent in developed countries and its prevalence rises with age.' Perforated colonic diverticular disease is a condition associated with high mortality and morbidity. Medical and surgical management of this condition has improved over the last two decades, but the mortality rate is largely unchanged.

Diverticula most commonly affect the sigmoid and descending colon in more than $(9 . \%)$ of patients. "' " When the diverticula become inflammed, the condition is called diverticulitis. Most of the inflammed diverticula are infected by bacteria, the bacterial infections may aggravate the symptoms and prolong the clinical course of the disease. Gram negative aerobes are the common causative bacteria. ${ }^{\gamma}{ }^{\circ}$-aminosalicylic acid ( ${ }^{-}$ ASA) is among the oldest anti-inflammatory agents in use today for the treatment of inflammatory bowel diseases. ${ }^{\wedge}$

When -ASA is taken orally as poorly absorbed formulations, it acts locally in the colon and it will be absorbed by colonic epithelial cells. "The effectiveness of this drug is related to its mucosal concentration."

--ASA appears to have advantage in obtaining symptomatic relief in an uncomplicated diverticular disease and in reducing the incidence of primary complications." The rationale for the use of ${ }^{-}$-ASA in the treatment of diverticular disease involves its antiinflammatory activity. ${ }^{\circ-A S A}$ inhibits some key factors of the inflammatory mediator cascade 
Irq $\mathrm{J}$ Pharm Vol. ${ }^{9} \& 1 \cdot$, No. ' ,

$r+1$.

(cyclooxygenase, platelet activating factor synthetase, thromboxane synthetase) ${ }^{1 r}$, inhibits the production of interleukin( $(\mathrm{L})^{-1}$ and free radicals "r and has intrinsic antioxidant activity.'

Poorly absorbed antibacterial agents may play a specific role in management of diverticulitis. ${ }^{10} \quad$ Trimethoprim and Sulfamethoxazole have occupied important roles in treatment of various commonly encountered infections ${ }^{17,}$ " and they play an important role in the management of many intra-abdominal infections including diverticulitis.'

During the last decade there has been interest in developing site-specific formulations for targeting drug delivery to colon. ${ }^{19}$ The colon is a site where both local and systemic drug delivery can take place.

Colonic drug delivery has gained increased importance not just for the delivery of drugs for the treatment of local diseases associated with the colon but also for the potential it holds for systemic delivery of proteins and therapeutic peptides. "The most critical challenge in such drug delivery approach is to preserve the formulation during its passage through the stomach and about first six meters of the small intestine."

Due to the distal location of colon in the gastrointestinal tract, a colon-specific drug delivery system should prevent drug release in the stomach and small intestine, and effect an abrupt onset of drug release upon entry into the colon. Such a system can be formulated by utilizing some specific conditions existing in the colon in comparison to other parts of the gastrointestinal tract."

The presence of colonic microflora has formed a basis for development of colonspecific drug delivery systems through many mechanisms of activation; such as: azoreduction and glycosidic bond hydrolysis. ${ }^{\text {r, }}{ }^{\text {ro }}$

Well known azo-drugs that exploit azoreductase for site-specific drug release are the --ASA prodrugs (e.g. olsalazine). These pass unaffected through the intestine where they are poorly absorbed, but are reduced by azoreductase secreted from colonic microflora. ${ }^{r "}$

\section{Materials and Instruments Materials}

The parent compounds (sulfamethoxazole and trimethoprim) were supplied from Nenevah Drug Industry (Iraq). All other chemicals used in preparations were supplied from Flukacompany (Germany).

\section{Instruments}

Melting points were determined on electrothermal CIA $q$... melting point apparatus and they are uncorrected.

The ultraviolet spectra were obtained via Carrywinn UV Varian UV-visible spectrophotometer (Australia).

The infrared absorbance was recorded by Buck 0. scientific IR spectrophotometer (USA).

Structures were drawn by Chemdraw Office r... software.

Thin-layer chromatography (TLC) was carried out on TLC plastic sheets silica gel $\uparrow$. Fo precoated, $r \cdot \times r \cdot \mathrm{cm}$, layer thickness $\cdot r \mathrm{~mm}$. The spots on the chromatograms were localized using UV light (rฯ 1 nm) (Whatmann). The solvent system employed for separation was (TA) which is composed from methanol: strong ammonia solution $(9 \curlywedge .0: 1.0)$.

\section{Experimental Methods}

\section{Synthesis of compound I}

Sulfamethoxazole ('r.70 $\mathrm{g}, . .0 \mathrm{~mole}$ ) was dissolved in a mixture of equal quantity $(17 \mathrm{ml})$ of each of conc. $\mathrm{HCl}$ and water in a beaker; the resulting solution was cooled by immersing in a bath of crushed ice; throughout the reaction, the reaction temperature was kept below $0^{\circ} \mathrm{C}$.

The cold solution of sodium nitrite $(\leqslant \mathrm{g}$, . $.0 \mathrm{~V}$ mole) in $r$. ml water was placed in a dropping funnel and then added drop by drop into the stirred solution of sulfamethoxazole in an ice bath; the reaction temperature was kept below $1 .{ }^{\circ} \mathrm{C}$ by adding few grams of crushed ice when necessary.

After the last addition, the resulting solution was stirred for ${ }^{\circ}$ minutes in an ice bath. A drop of the solution diluted with ( $\varepsilon$ drops) of water was tested with potassium iodide-starch paper; if no immediate blue color was obtained at the point of contact with paper, a further $1 \mathrm{ml}$ of sodium nitrite solution was added, and the solution tested again after ${ }^{\circ}$ minutes.

Further adding and testing were continued until an immediate blue color was obtained.

The salicylic acid solution was prepared by mixing salicylic acid $(7.9 \mathrm{~g}, \cdot .0$ mole) with ( $\{0$ $\mathrm{ml}$ ) of $1 . \% \mathrm{NaOH}$ in a beaker immersed in the ice bath. The solution was vigorously stirred and the temperature kept below $0^{\circ} \mathrm{C}$; this was assisted by a direct addition of crushed ice.

The cold diazonium salt solution with few grams of crushed ice were placed in a dropping funnel and added drop by drop to the stirred salicylic acid solution in an ice bath; 
Irq $\mathrm{J}$ Pharm Vol. ${ }^{9} \& 1 \cdot$, No. ',

$r, 1$.

orange color was developed and orange crystals soon separated giving compound I.

After the diazonium salt solution was added; the mixture was allowed to stand in ance bath for $r$. minutes; filtered off and the crystals washed three times with cold water, then re-crystallized from ethanol. The

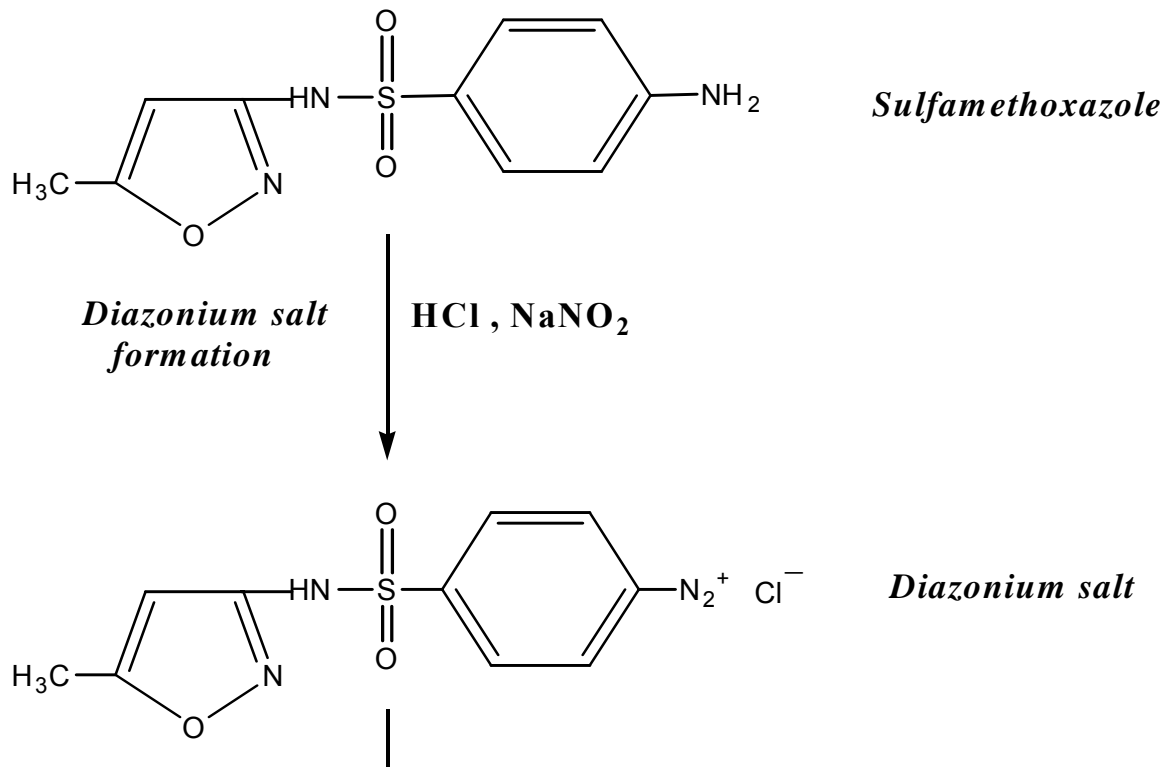

Coupling reaction with salicylic acid

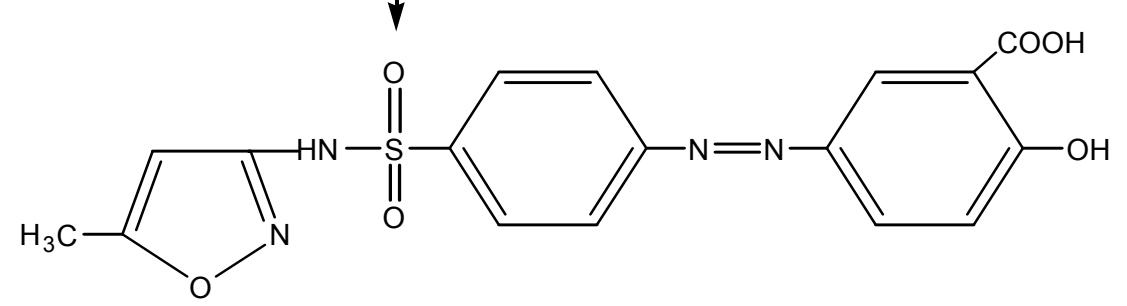

Compound ( I )

4-(salicylic acid-5"-azo-yl)-N-(5'-methyl-3'-isoxazolyl)benzene-sulfonamide

Scheme '. Synthesis of compound I

Compound I has the following data: the melting point was $\left(1 \wedge 0_{-} \wedge \wedge v^{\circ} \mathrm{C}\right)$, the percentage of yield was $(\wedge \circ \%)$, the molecular formula was established as $(\mathrm{C} \mid \vee \mathrm{H}) \leqslant N \leqslant O \curlyvee S)$ and the Rf value was $(\cdot .7)$.

compound purity was established by thin-layer chromatography using TA solvent and the TLC result showed that only a single spot was observed.

\section{Synthesis of compound II}

Trimethoprim ( $1 \leqslant .0 \mathrm{~g}, . .0$ mole) was dissolved in a mixture of equal quantity ( $r$ r ml) of each of conc. $\mathrm{HCl}$ and water in a beaker; the resulting solution was cooled by immersing in a bath of crushed ice; throughout the reaction, the temperature was kept below $0^{\circ} \mathrm{C}$. The cold solution of sodium nitrite $(\vee . \wedge \vee \mathrm{g}$, $.11 \leq \mathrm{mole})$ in $\leqslant \cdot \mathrm{ml}$ water was placed in a dropping funnel and then added drop by drop into the stirred solution of trimethoprim in an ice bath; the reaction temperature was kept below $1 .{ }^{\circ} \mathrm{C}$ by adding few grams of crushed ice when necessary.

After the last addition, the resulting solution was stirred for 0 minutesin an ice bath. A drop of the solution diluted with $\varepsilon$ drops of water was tested with potassium iodide-starch paper; if no immediate blue color was obtained at the point of contact with paper, a further $(l \mathrm{ml})$ of sodium nitrite solution was added, and the solution tested again after ${ }^{\circ}$ minutes. Further adding and testing were continued until an immediate blue color was obtained. 
Irq $\mathrm{J}$ Pharm Vol. ${ }^{9} \& 1 \cdot$, No. ${ }^{\prime}$,

$r, 1$.

The salicylic acid solution was prepared by mixing salicylic acid ( $1{ }^{\top} . \wedge \mathrm{g}, \cdot .1$ mole) with ( 9 . $\mathrm{ml}$ ) of $1 . \% \mathrm{NaOH}$ in a beaker immersed in the ice bath, this solution was vigorously stirred and the temperature kept below $0^{\circ} \mathrm{C}$; this was assisted by a direct addition of crushed ice.

The cold diazonium salt solution with few grams of crushed ice were placed in a<smiles>COc1cc(Cc2cnc(N)nc2N)cc(OC)c1OC</smiles>

\section{Trimethoprim}

$\mathrm{H}_{3} \mathrm{CO}^{\prime}$

$\mathrm{H}_{2} \mathrm{~N}$

dropping funnel and added drop by drop to the stirred salicylic acid solution in an ice bath; red color was developed and red crystals soon separated giving compound II. After the diazonium salt solution was added; the mixture

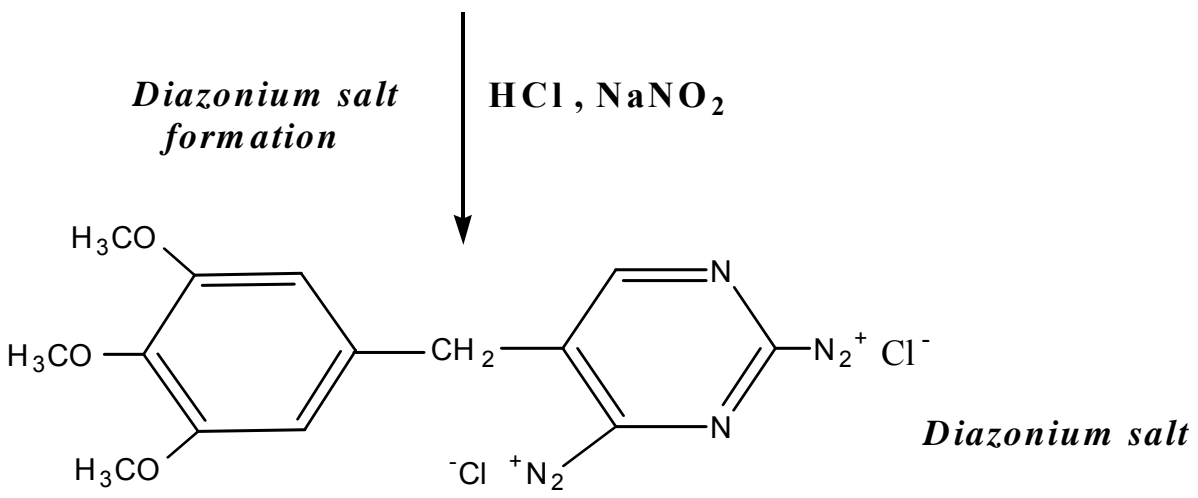

\section{Coupling reaction with salicylic acid}

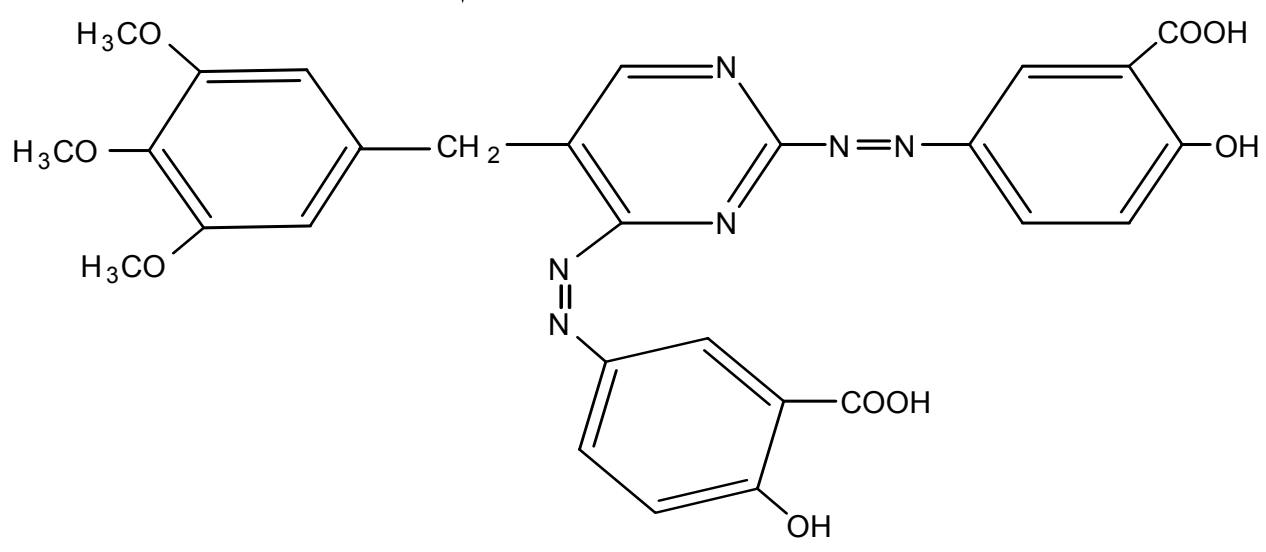

\section{Compound ( II)}

2,4--di(salicylic acid-5"-azo-yl)-5-(3',4',5'-trim ethoxybenzyl)pyrimidine Scheme r. Synthesis of compound II Compound II has the following data: the melting point was (rro-

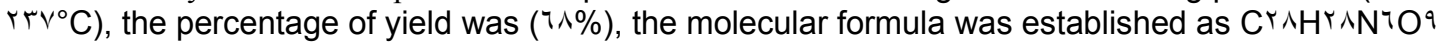
and the Rf value was $\cdot .{ }^{\circ} \mathrm{V}$. 
Irq $\mathrm{J}$ Pharm Vol. ${ }^{9} \& 1 \cdot$, No. ${ }^{\prime}$,

r.l.

was allowed to stand in an ice bath.for $r$. minutes; filtered off and the crystals washed three times with cold water, then re-crystallized from ethanol.

The compound purity was established by thin-layer chromatography using TA solvent and the TLC result showed that only a single spot was observed.

\section{In vitro stability studies}

In order to obtain information on the stability of compounds I and II in $(. .0 \mathrm{M})$ hydrochloric acid buffer $\left(\mathrm{pH}, \mathrm{r}^{\mathrm{r}}\right)$ and in. $.0 \mathrm{M}$ phosphate buffer $(\mathrm{pH} \vee . \varepsilon)$, the following procedure was used: r^A sample $(\cdot r \varepsilon$ mole) of mutual prodrug was introduced into a conical flask

Table 1. Kinetic data obtained from the stability studies

\begin{tabular}{|c|c|c|c|c|}
\hline Compound number & $A$ & $\lambda_{\max }$ & $\begin{array}{c}a \\
\left(\text { molex }{ }^{\prime} \cdot{ }^{\top}\right)\end{array}$ & $\varepsilon$ \\
\hline Compound ( I ) &. .170 & $r \cdot r \mathrm{~nm}$ & $\tau \Lambda \cdot . r \mu$ & 071.98 \\
\hline Compound ( II ) & $\because v \leqslant \varepsilon$ & $\varepsilon \cdot \wedge \mathrm{nm}$ & Tג. & $0 \leqslant 7.0 Y$ \\
\hline Compound (II ) &.$V 9 Y$ & IAr $\mathrm{nm}$ & $T \Lambda \cdot . r \mu$ & $0 \wedge Y .17$ \\
\hline
\end{tabular}

containing $(1 \cdots \mathrm{ml})$ of $\mathrm{HCl}$ buffer; the resulting solution was kept at a constant temperature $\left(r v \pm{ }^{\circ} \mathrm{C}\right)$ using a water bath with gentle stirring. The absorbance of this solution was determined by using $r \mathrm{~cm}$ quartz UV cell. The following formula was applied ${ }^{\text {rq }}$ to calculate the absorbance coefficient $(\varepsilon)$ of the solution:

$A=\varepsilon \mid a \quad$ where $a=$ Conc. of mutual prodrug at zero time.

Since the magnitude of absorbance coefficient was known, it is possible to determine the conc. of the compound I remaining at different time intervals using the following formula:

$A=\varepsilon \mid x \quad$ where $x=$ Conc. of mutual prodrug remaining.

A sample ( $r \mathrm{ml}$ ) was taken from the reaction flask, shaken with an equal volume of chloroform in order to remove the interfering products which could be released from hydrolysis of the mutual prodrug. The aqueous portion was estimated on UV spectrophotometer to determine the amount of mutual prodrug remaining. Every r. minutes, the above procedure was preceded for three hours and the decrease in the prodrug concentration with the time was monitored.

To examine the stability of mutual prodrug in phosphate buffer, the same procedure used to determine the stability in $\mathrm{HCl}$ buffer was followed; except that the phosphate buffer replaced the $\mathrm{HCl}$ buffer and the UV data were taken every r. minutes for six hours. The magnitudes of the solution absorbance at time zero and the absorbance coefficient of both compounds are summarized in table '.

\section{Release study in rat fecal matter}

A sample (. YYV g, $070.9 \times 1 .-7$ mole) of compound I was dissolved in sufficient volume of phosphate buffer $(\mathrm{pH} \vee . \varepsilon)$ to achieve a final concentration of $\mu . . \mu \mathrm{g} / \mathrm{ml}$. Fresh fecal material of rats weighed about $1 \mathrm{~g}$ was placed in test tubes.

To each test tube, I $\mathrm{ml}$ of compound I solution was added; diluted to $\bullet \mathrm{ml}$ with phosphate buffer to achieve a final concentration of $\tau \cdot \mu \mathrm{g} / \mathrm{ml}$. the test tubes were incubated at a constant temperature $\left(r v \pm{ }^{\circ} \mathrm{C}\right)$ using a water bath. Every $r \cdot$ minutes, one test tube was removed from a water bath and its contents were shaken with ${ }^{\circ} \mathrm{ml}$ of chloroform. The aqueous portion was estimated on UV spectrophotometer to determine the amount of compound I remaining; this procedure proceeded for seven hours.

The above procedure was used to detect the hydrolysis of azo linkage para to methyl pyrimidine of compound II in rat fecal matter by using $. r 0 \leq \mathrm{g}, 09 \mathrm{v} .19 \times 1 \cdot-7$ mole. In addition, the same procedure was used to detect the hydrolysis of azo linkage ortho to methyl pyrimidine of compound II in rat fecal matter by using • rry g, $00 \cdot$ rox $\cdot-7$ mole.

The calculations of the release study were carried out as for the stability study. The results obtained from the release study are listed in tables $r$, $\varepsilon$ and $\bullet$. All the kinetic procedures (stability studies in $\mathrm{HCl}$ buffer; in phosphate buffer and release study in rat fecal matter) were carried out three times. 
Irq $\mathrm{J}$ Pharm

Vol. ${ }^{9} \& 1 \cdot$, No. ',

$r \cdot 1$.

\section{Results and Discussion}

Trimethoprim and sulfamethoxazole may be active against many aerobic gram-negative bacteria which represents the common causative micro-organism in a diverticulitis. " A variety of adverse effects were reported with the using of trimethoprim and sulfamethoxazole; such as: hyper-sensitivity reactions, ${ }^{r}$ hematological side effects and crystalluria."

- ASA is very effective in diverticulitis but it is absorbed mainly in the upper gastrointestinal tract that it usually fails to reach the colon leading to significant adverse effects. Therefore, to overcome this problem, colonic drug delivery has been developed for the topical treatment of diverticulitis.

In this study, a mutual azo prodrug of sulfamethoxazole with salicylic acid and a mutual azo prodrug of trimethoprim with salicylic acid were synthesized. The azo linkages in both mutual prodrugs were proposed to be broken in colon by the action of azo-reductase produced by colonic microflora. In the first mutual prodrug, the hydrolysis of azo linkage leads to release of the sulfamethoxazole and ${ }^{-A S A}$. While in the second mutual prodrug, the hydrolysis of azo linkages leads to release one mole of trimethoprim and two moles of 0 -ASA. Trimethoprim or sulfamethoxazole may be used to treat aerobic gram-negative bacterial infection in a diverticulitis, while -ASA may reduce the inflammation in this disease.

\section{Synthesis of compound I}

A primary aromatic amine (sulfamethoxazole) was dissolved in a cold aqueous mineral acid solution then treated with sodium nitrite to form a diazonium salt, this process called a diazotization of primary amine.

Two important points must be taken into consideration in the preparation of diazonuim salt; which are: the amine is comparatively a weak base, so that, a certain amount of amine will be produced by salt hydrolysis unless an excess of acid is present; and the reaction mixture must be kept very cold during the process (the reaction is exothermic); otherwise, the diazonium salt may be partially converted into the corresponding hydroxyl compound. $^{\text {ro }}$

The aromatic ring undergoing attack by the diazonium ion must in general contain a powerful electron-donating group $\left(\mathrm{OH}, \mathrm{NH}^{r}\right.$, NHR). Substitutÿÿÿÿusually occurs at para position to the activating group. The aromatic ring of salicylic acid is usually attacked by the diazonium ion at position para to $\mathrm{OH}$, which is the same position meta to carboxylic acid group.

The principal peaks of IR spectrum of compound I are listed in table $r$. The disappearance of absorbance band at $r \leqslant r q$ $\mathrm{cm}-1$ of primary amine of sulfamethoxazole and the appearance of a weak absorbance band at l $\leqslant \wedge \mathrm{cm}$-1 of azo group (unsymmetrical p-substituted azo benzene) confirmed the formation of azo compound, these data were quite in agreement with the structure of compound I.

The U.V. spectrum of compound I in an aqueous acidic solution $\left(\mathrm{pH}, \mathrm{r}^{\mathrm{r}}\right.$ ) shows two maximum absorbencies, the first $\lambda \max$ at $r \mathrm{r}$ $\mathrm{nm}$ and the second $\lambda \max$ at $17 / \mathrm{nm}$.

\section{Synthesis of compound II}

One mole of trimethoprim was dissolved in a cold aqueous mineral acid solution then treated with two moles of sodium nitrite to form an intermediate having two diazonium ions according to a diazotization of primary amine.

The diazonium ions may be attacked by two moles of salicylic acid to form compound II. The substitution usually occurs at position (0) of salicylic acid because of this position is para to $\mathrm{OH}$ group and meta to carboxylic acid group.

The principal peaks of IR spectrum of compound II are listed in table $r$. The disappearance of absorbance bands at $r \leqslant 1 r$, $r \Sigma \vee \wedge \mathrm{cm}-1$ of the two primary amines of trimethoprim and the appearance of weak absorbance bands at $1 \leqslant 9 \leqslant, 10 \leqslant \cdot \mathrm{cm}-1$ of azo groups confirmed the formation of diazo compound; these data were quite in agreement with the structure of compound II.

The UV spectrum of compound II in an aqueous acidic solution $\left(\mathrm{pH}, \mathrm{p}^{\mathrm{r}}\right.$ ) shows two maximum absorbencies, the first $\lambda \max$ at $r . q$ $\mathrm{nm}$ and the second $\lambda$ max at $r v \cdot \mathrm{nm}$.

\section{In vitro kinetic studies}

Compound I in $\cdot . \circ \mathrm{M}$ hydrochloric acid buffer $(\mathrm{pH} \quad, . r)$ showed negligible release of sulfamethoxazole and ${ }^{\circ}$-ASA. Whereas in phosphate buffer ( $\mathrm{pH} \vee . \varepsilon)$, only ( $17 . \wedge \mathrm{r} \%$ ) release was observed over a period of six hours. The objective of bypassing the upper gastrointestinal tract with minimum prodrug release was achieved.

Further study in rat fecal matter was carried out to confirm the colonic reduction of azo 
r.l.

Table r. The I.R. spectra of compounds I and II

\begin{tabular}{|c|c|c|c|c|c|}
\hline $\begin{array}{l}\text { Compound } \\
\text { number }\end{array}$ & $\begin{array}{l}\text { Phenolic } \mathrm{OH} \\
\text { stretching } \\
\text { (H-bonded) }\end{array}$ & $\begin{array}{l}\text { Carboxylate } \\
\text { anion } \\
\text { stretching }\end{array}$ & $\begin{array}{l}(-\mathrm{N}=\mathrm{N}-) \\
\text { stretching }\end{array}$ & $\begin{array}{l}(\mathrm{C}-\mathrm{N}) \\
\text { stretching }\end{array}$ & $\begin{array}{l}(\mathrm{C}-\mathrm{H}) \text { bending }-1, \mathrm{r}, \mathrm{O} \\
\text { trisubstituted } \\
\text { benzene }\end{array}$ \\
\hline Compound ( I ) & rTr人 & $10 \Lambda \cdot, 1 \varepsilon .0$ & $1 \leqslant \Lambda T$ & 1.19 & $10 ., 791$ \\
\hline Compound ( II ) & $\begin{array}{l}\text { TrOV } \\
\text { TI90 }\end{array}$ & $\begin{array}{l}171 Y, 1 T \Lambda \varepsilon \\
1091,1 T V A\end{array}$ & $\begin{array}{l}10 \leqslant . \\
1 \leqslant 9 \leqslant\end{array}$ & $\begin{array}{l}1.17 \\
1.71\end{array}$ & $\begin{array}{l}A \Lambda V, V) \varepsilon \\
\Lambda Y \varepsilon, T V Y\end{array}$ \\
\hline
\end{tabular}

Table $r$. Kinetic data for release study of compound I in rat fecal matter

\begin{tabular}{|c|c|c|c|c|c|}
\hline Absorbance & $\begin{array}{l}\text { Time } \\
(\min .)\end{array}$ & $\begin{array}{c}x \\
\left.(\text { mole } x) \cdot{ }^{\top}\right)\end{array}$ & $\begin{array}{c}(a-x) \\
\left.(\text { molex }) \cdot{ }^{7}\right)\end{array}$ & $a /(a-x)$ & $\ln (a / a-x)$ \\
\hline .047 & $r$. & $\sum \vee 7.9 Y$ & $\wedge \Lambda .91$ & 7.47 & 1.10 \\
\hline $.0 Y T$ & 7. & $\{70.07$ & $1 \cdots r \varepsilon$ & $0.7 \varepsilon$ & $1 . V T$ \\
\hline$\because 0 . \varepsilon$ & 9. & $\varepsilon \varepsilon \Lambda . Y_{0}$ & 118.70 & $\varepsilon . \wedge 1$ & $1.0 \mathrm{~V}$ \\
\hline$\cdot \leqslant V T$ & Tr. & $\varepsilon r \cdot . \wedge$. & $1 \leq 0.1$. & r.9. & 1.47 \\
\hline$\therefore \leqslant 09$ & 10. & $\varepsilon \cdot \wedge . \vee 1$ & $10 V .19$ & T.7. & 1.51 \\
\hline.$\leq T r$ & $1 \wedge$. & r人o.1. & $1 \wedge \cdot . \wedge$. & $r .1 T$ & $1.1 \varepsilon$ \\
\hline$\cdot \leqslant 1 \leqslant$ & TI. & rчA. r & 19V.AV & T.^T & 1.0 \\
\hline. & $T \varepsilon$. & $r 11.07$ & ros.r $T$ & T.YT & $\because \wedge$. \\
\hline 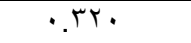 & $r V \cdot$ & YAะ.r T & YNI.0 & $r .1$ & $\because V \cdot$ \\
\hline .977 & r... & rrq.A9 & rrq.. & $1 . V Y$ & $.0 \leqslant$ \\
\hline$\cdot r \leqslant r$ & קזי & YIT.01 & $r \leqslant 9 . r Y$ & 1.74 & $\because \leqslant \Lambda$ \\
\hline $.1 \%$ & ז. & $110.1 \%$ & $\varepsilon 1 \cdot . \cdot V$ & $1 . r \Lambda$ & 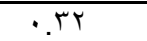 \\
\hline$\because \wedge \wedge$ & $r q$. & $\vee \wedge . .7$ & $\varepsilon \wedge \vee . \wedge \varepsilon$ & 1.17 & .10 \\
\hline$\cdot$ & $\varepsilon Y$. & . & 070.9. & 1 & . \\
\hline
\end{tabular}

$(a)=$ conc. of compound (I) at time zero and equal to $\left(070.9 \times 1 \cdot{ }^{-9}\right.$ mole $),(x)=$ conc. of compound I remaining for any time. 
Irq J Pharm Vol. ${ }^{9} \& 1 \cdot$, No. ',

$r \cdot 1$.

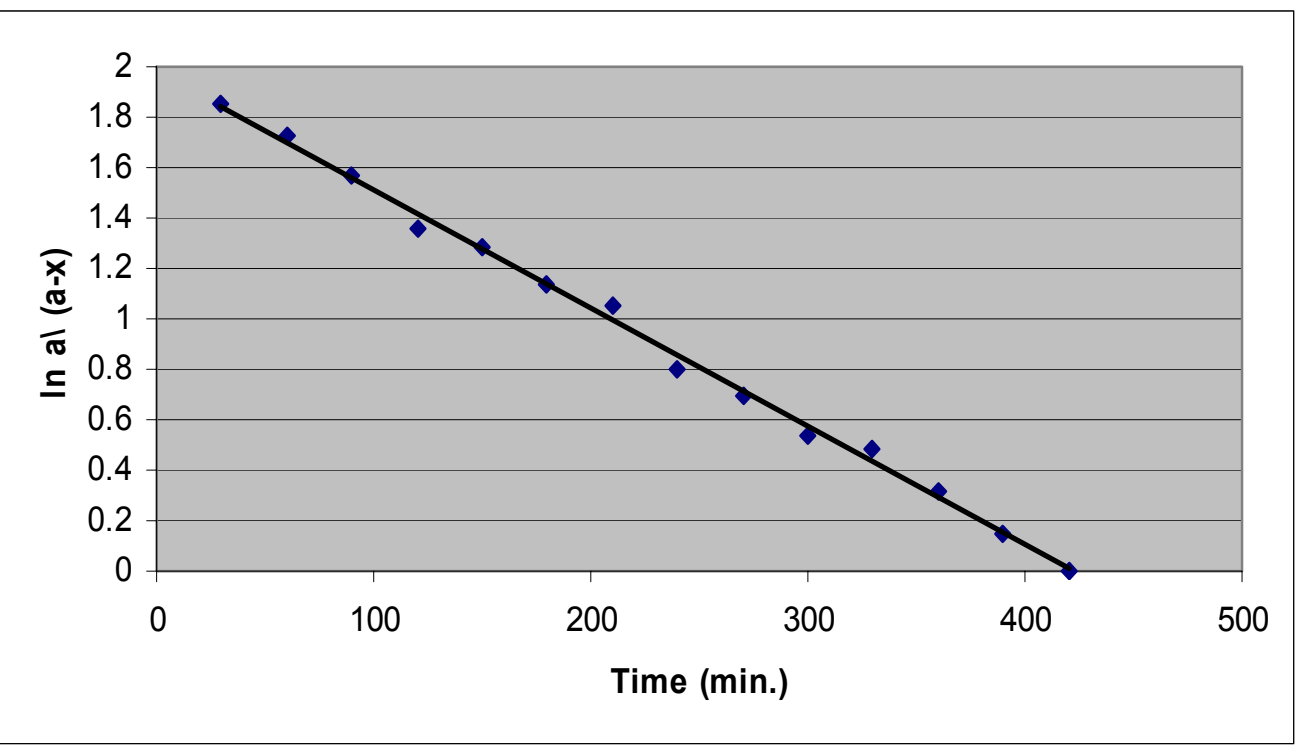

Figure 1. The slope of release study for compound I in rat fecal matter

prodrug over a period of seven hours, compound I showed (Ar.1^ \%) cumulative release of sulfamethoxazole and O-ASA.The release study of compound I in rat fecal matter followed first order kinetics (Figure 1), the t. . (average of three trials) of compound I

Table $r$ shows the kinetic data obtained from the release study of compound I in rat fecal matter at $r r^{\circ} \mathrm{C}$ and $\lambda \max =r \cdot r \mathrm{~nm}$ was found to be $1 \leqslant \wedge$. $\{$ minutes, whereas the rate constant (k) was found to be $\left\{. T \vee \times 1 .{ }^{-r} \pm \ldots \cdots\right.$. Compound II, in $\because .0 \mathrm{M}$ hydrochloric acid buffer $(\mathrm{pH},, r)$ showed negligible release of trimethoprim and O-ASA. Because of compound (II) has two azo groups may be hydrolyzed in phosphate buffer ( $\mathrm{pH} \vee . \varepsilon)$, two kinetics may be followed. First is the kinetic of an azo group para to methyl pyrimidine; second is the kinetic of an azo group ortho to methyl pyrimidine. The last group is less stable than the first one. The hydrolysis of azo group para to methyl pyrimidine in phosphate buffer $(\mathrm{pH} \vee . \varepsilon)$ showed only $\mathrm{K}$. r $r \%$ release over a period of six hours whereas in rat fecal matter over a period of seven hours, this group showed AV.VA \% cumulative release of trimethoprim and 0 -ASA. Table $\varepsilon$ shows the kinetic data obtained from the release study of azo group para to methyl pyrimidine of compound $\mathrm{II}$ in rat fecal matter at $\mathrm{r}^{\circ} \mathrm{C}$ and $\lambda \max =\varepsilon \cdot \wedge \mathrm{nm}$.

Table «. Kinetic data for release study of azo group para to methyl pyrimidine of compound II in rat fecal matter.

\begin{tabular}{|c|c|c|c|c|c|}
\hline Absorbance & $\begin{array}{l}\text { Time } \\
\text { (min.) }\end{array}$ & $\begin{array}{c}x \\
\left.(\text { mole } x) \cdot{ }^{7}\right)\end{array}$ & $\begin{array}{c}(a-x) \\
\left(\text { molex }{ }^{7}{ }^{7}\right)\end{array}$ & $a \mid(a-x)$ & $\ln (a \mid a-x)$ \\
\hline$\theta 0 \leqslant 0$ & $r$. & $\varepsilon q \wedge . \leqslant \wedge$ & $9 \wedge . \vee 1$ & 7.0 & $1 . \wedge$. \\
\hline .0 OYO & 7. & $\varepsilon \wedge \cdot . q$ & $11 V .1$. & 0.1. & 1.74 \\
\hline $.0 . \mathrm{V}$ & 9. & $\sum 7 r . \wedge 9$ & Tr.r. & $\varepsilon . \leqslant \wedge$ & 1.0 \\
\hline$\because \leqslant q r$ & IT. & $\leqslant 0 . .1$. & $1 \leqslant V .9$ & $\varepsilon .7$ & $1 . \varepsilon$ \\
\hline$\because \leqslant \vee \wedge$ & 10. & $\sum M V .01$ & 109.71 & $r . V \varepsilon$ & 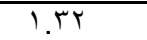 \\
\hline. .507 & $1 \wedge$. & हाV.Mा & $189 . \wedge 1$ & T.MT & I.Y. \\
\hline.$\leqslant ा T$ & Y. & rVV.Tr & Y19.07 & T.VY & 1 \\
\hline$\because r V \leq$ & $T \varepsilon$. & $r \leq 1.91$ & Y00.Y & T.TE & .10 \\
\hline$\because \mu 1 \wedge$ & $T V \cdot$ & $r q . .9 \varepsilon$ & r.T.ro & 1.90 & $\cdot .7 V$ \\
\hline.$r q \wedge$ & $r \ldots$ & TVY.Tr & TYE.0T & $1 . \wedge \varepsilon$ & .71 \\
\hline.$Y T V$ & קז. & $Y \backslash \nearrow . \wedge 1$ & $\Gamma \wedge \cdot r \Lambda$ & $1.0 \mathrm{~V}$ & $\because \leqslant 0$ \\
\hline
\end{tabular}


Irq J Pharm Vol. ${ }^{9} \& 1 \cdot$, No.,

r. I.

\begin{tabular}{|c|c|c|c|c|c|}
\hline .197 & . & $189.0 \mathrm{~V}$ & $\varepsilon \mid V . T Y$ & $1 . \leqslant r$ & $\cdot .47$ \\
\hline $.11 \pi$ & 49. & $1 . T .7 \varepsilon$ & $\leqslant 94.00$ & 1.41 &. .19 \\
\hline . & $\varepsilon r$. & . & 097.19 & 1 & . \\
\hline
\end{tabular}

(a) = conc. of compound II) at time zero and equal to $\left(09 \mathrm{~V} .19 \times 1 .^{-1} \mathrm{~mol}\right),(\mathrm{x})=$ conc. of compound II remaining for any time.

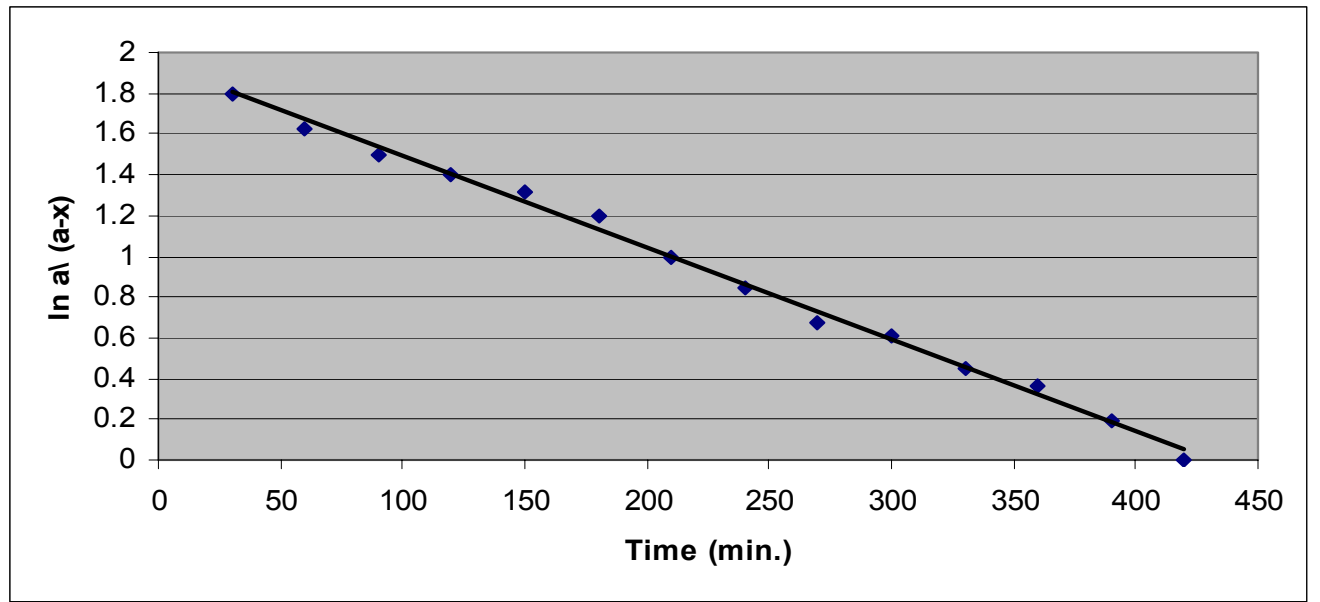

Figure $r$. The slope of release study of azo group para to methyl pyrimidine of compound II in rat fecal matter.

This release study followed first order kinetics (Figure $r$ ), the t.. (average of three trials) of compound II was found to be 10V.0 minutes, whereas the rate constant $(k)$ was found to be $\left\{.\left\{\times 1 \cdot \cdot^{-r} \pm \cdot \cdots \cdot\right.\right.$.

The hydrolysis of azo group ortho to methyl pyrimidine in phosphate buffer $(\mathrm{pH} \quad \vee . \varepsilon)$ showed only $19.1 \% \%$ release over a period of six hours whereas in rat fecal matter over a period of seven hours, this group showed $\wedge . . \wedge$ \% cumulative release of trimethoprim and 0 -ASA.Table 0 shows the kinetic data obtained from the release study of azo group ortho to methyl pyrimidine of compound II in rat fecal matter at $r v^{\circ} \mathrm{C}$ and $\lambda \max =1 \wedge r \mathrm{~nm}$.

Table ${ }^{\circ}$. Kinetic data for release study of azo group ortho to methyl pyrimidine of compound II in rat fecal matter.

\begin{tabular}{|c|c|c|c|c|c|}
\hline Absorbance & $\begin{array}{l}\text { Time } \\
\text { (min.) }\end{array}$ & $\begin{array}{c}x \\
\left(\text { molex }+{ }^{7}\right)\end{array}$ & $\begin{array}{c}(a-x) \\
(\text { molex } \\
\end{array}$ & $a \mid(a-x)$ & $\ln (a \mid a-x)$ \\
\hline $.0 \leq \Lambda$ & $r$. & $\varepsilon v \cdot r q$ & V9.人7 & $7 . \wedge 9$ & 1.94 \\
\hline .049 & 7. & $\sum 7 Y .91$ & AV.T & $7 . \mu$. & $1 . \wedge \varepsilon$ \\
\hline $.01 \mathrm{~V}$ & 9. & $\varepsilon \leqslant r .71$ & $1.7 .7 \varepsilon$ & 0.17 & $1.7 \varepsilon$ \\
\hline$\because \leqslant 90$ & $\pi$. & $\varepsilon r \varepsilon .91$ & Tro.r & $\varepsilon .4 q$ & $1 . \leqslant \wedge$ \\
\hline 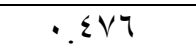 & 10. & 8.9 .17 & $1 \leqslant 1.99$ & r.q. & 1.17 \\
\hline.$\leqslant \varepsilon \cdot$ & $1 \wedge$. & rVV.VT & IVY_Eq & $r .19$ & 1.17 \\
\hline.$\leqslant 1 V$ & rI. & rov.10 & 194.\&. & T.人T & 1.0 \\
\hline$\cdot r \vee \wedge$ & $T \varepsilon$. & TY乏.V & TYO.01 & T. $\varepsilon \varepsilon$ & .199 \\
\hline .419 & TV. & TVT.VE & TVY.01 & 1.99 & .79 \\
\hline.$r \wedge r$ & $r \ldots$ & $r \leqslant Y . \wedge 0$ & $r \cdot V . \varepsilon$. & 1.19 & .01 \\
\hline . & rr. & $199.7 V$ & $r 0 . . \leqslant \Lambda$ & $1.0 \mathrm{~V}$ &.$\leqslant 0$ \\
\hline $.1 \wedge$. & r. & $10 \leqslant . r q$ & $r 90.17$ & 1.49 & . \\
\hline
\end{tabular}


Irq J Pharm Vol. ${ }^{9} \& 1 \cdot$, No. ',

r.l.

\begin{tabular}{|c|c|c|c|c|c|}
\hline$\because \wedge \varepsilon$ & rq. & $V I . V V$ & $\varepsilon \vee \wedge . \leqslant \wedge$ & 1.10 & $.1 \varepsilon$ \\
\hline - & $\varepsilon r$. & . & 00. Y & 1 & - \\
\hline
\end{tabular}

(a) = conc. of compound (II) at time zero and equal to $\left.(00 \cdot . \mathrm{Y} 0 \times)^{-{ }^{-1}} \mathrm{~mole}\right),(\mathrm{x})=$ conc. of compound ( II ) remaining for any time.

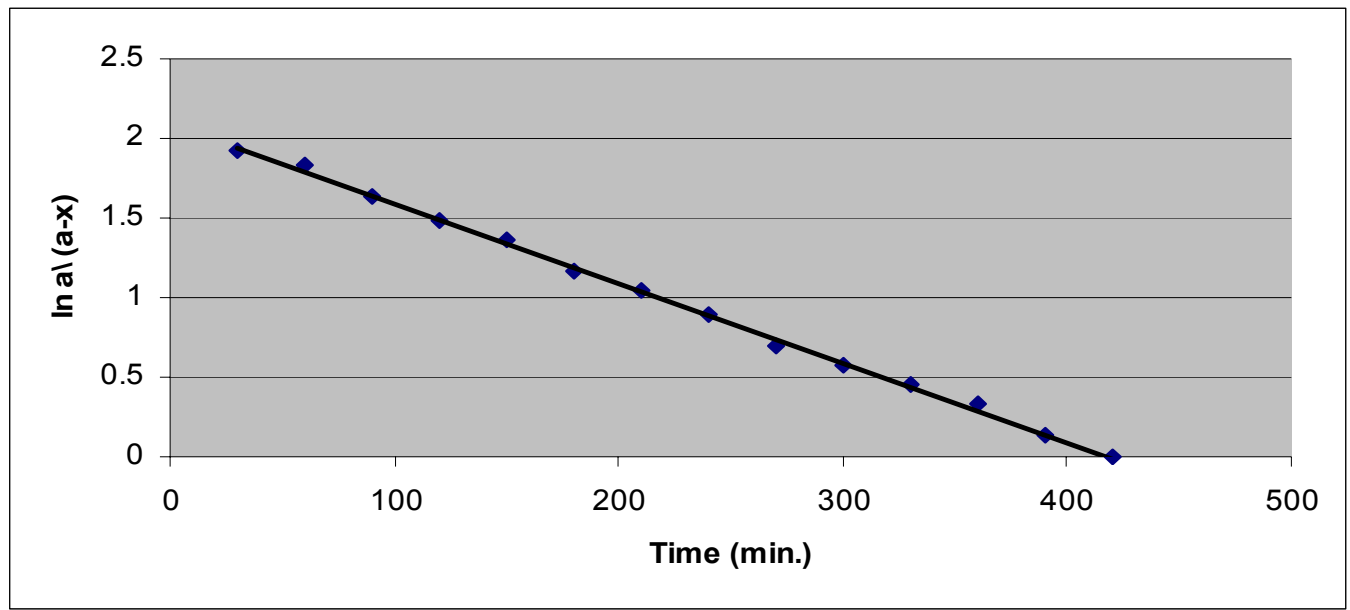

Figure $r$. The slope of release study of azo group ortho to methyl pyrimidine of compound II in rat fecal matter

This release study followed first order kinetics (Figure r), the t. . (average of three trials) of compound II was found to be 1 r . 7 minutes whereas the rate constant $(k)$ was found to be ox $1^{-r} \pm \cdot \ldots 1$.

\section{Conclusion}

This study reports the synthesis and in vitro kinetic studies of two mutual azo prodrugs. The first of equimole of sulfamethoxazole and -ASA; the second of one mole of trimethoprim and two moles of ${ }^{-}$-ASA for their colon targeting delivery to treat a diverticulitis. Introduction of azo linkages in these mutual prodrugs has enhanced the aqueous solubility of -ASA, sulfamethoxazole and trimethoprim, so that with minimum absorption in upper gastrointestinal tract. These mutual prodrugs would be directly delivered to colon and release the active compounds by the reducing action of azo reductase secreted by the colonic microflora.

\section{References}

1. Stollman $\mathrm{NH}$, Baskin JB. Diagnosis and management of diverticular disease of the colon in adults. Am J Gastroenterol 1999; $9 \leqslant: r 11 \cdot-r \mid r)$.

$r$. Salzman H, Dustin L. Diverticular disease: diagnosis and treatment. Am Fam Phys r...0;VY:IYr.-IYrs.

r. Ferzoco LB, Raptopoulos V , Silen W. Acute diverticulitis. Now Engl J Med 1991; rTA:10Y1-17rT.

£. Stollman NH, Raskin JB. Diverticular disease of the colon. $\mathrm{J}$ Clin Gastroenterol $1999 ;$ Y 9 :r $1-$ ror.

- Floch MH. A hypothesis: Is diverticulitis a type of inflammatory bowel disease? J Clin Gastroenterol $r \ldots r ; \varepsilon \cdot:|r|-1 r_{0}$.

7. Antonio T, Giovanni B, Giorgetti GM, Elisei W. Assessment of intestinal bacterial overgrowth in uncomplicated acute diverticulitis of the colon. World $J$ Gastroenterol $r \ldots 0 ; 11:$ rVVT-rVV7.

v. Brook I, Frazier EH. Aerobic and anaerobic microbiology in intra-abdominal infections associated with diverticulitis. J Med Microbiol $r \ldots . . ; \varepsilon 9: \wedge r V_{-} \wedge r$.

^. Christel R, Bruno L, Laurent D, Philippe L, et al. Intestinal anti-inflammatory effect of -aminosalicylic acid is dependent on peroxisome proliferator activated receptor. $J$ Experimental Medicine $r \ldots .0 ; r \cdot 1: 1\} \cdot 0_{-}$ 1410 .

9. Zhou SY, Fleisher LH, Zimmermann EM. Intestinal metabolism and transport of ${ }^{\circ}$ aminosalicylate. Drug Metab Dispos $1999 ; Y \vee: \leqslant \vee 9-\leqslant \wedge 0$.

1. Frieri G, Giacomelli RM, Pimpo G, Caprilli R. Mucosal o-aminosalicylic acid concentration inversely correlates with severity of colonic inflammation in patients 
Irq $\mathrm{J}$ Pharm Vol. ${ }^{9} \& 1 \cdot$, No. ${ }^{\prime}$,

r.l.

with ulcerative colitis. Gut $r \ldots ; \leqslant \vee$ : $\leqslant 1 \cdot-$ «) $\varepsilon$.

11. Giuseppe C, Fanigliulo L, Cavallaro LG, Giovanni A, et al. Prevention of complications and symptomatic recurrences in diverticular disease with mesalazine. Dig Dis Sci r..v; or: rqr rq 1.

1r. Eliakim R, Rachmilewitz D. Potential mediators in inflammatory bowel disease.

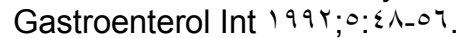

1\%. Grisham MB. Oxidants and free radicals in inflammatory bowel disease. Lancet $199 \leqslant ; r \leqslant \varepsilon: 109-\wedge 71$.

1 ร. Goncalves E, Almeida LM, Dinis TC. Antioxidant activity of 0 -aminosalicylic acid against peroxidation of phosphatidylcholine liposomes in the presence of alpha-tocopherol: A synergistic interaction. Free Rad Res 199人:r9:0r-77.

10. Stollman N, Raskin JB. Diverticular

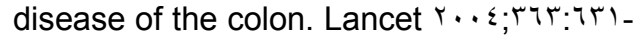
7 ra.

17. Masters AP, Thomas AB, Zurlo J, Miller $D Q$, et al. Trimethoprim and sulfamethoxazole revisited. Arch Intern Med r..r; $\mid 7 r: \varepsilon \cdot r_{-} \varepsilon 1$.

ro. Rubinstein A, Radai R, Pathak S, Rokem JS. A potential colon-specific drug delivery carrier. Pharm Res 199r;1 : r०人_r r r.

r.. Clancy MJ, Ana LS, John FG. Prodrugs for amines. Molecules r... $;$; r:019_orv.

$r v$. Sandborn W. Rational selection of oral ${ }^{\circ}$ aminosalicylate formulations and prodrugs for the treatment of ulcerative colitis. Am J Gastroenterol r...r;qv:rqrq_rq

$r \wedge$. Nagpal D, Singh R, Gairola N, Vodhankar $\mathrm{SL}$, et al. Mutual azo prodrug of ${ }^{-}$ aminosalicylic acid for colon targeted drug delivery: synthesis, kinetic studies and pharmacological evaluation. Indian $\mathrm{J}$ Pharmace Sci $\uparrow \ldots 7 ; 7 \wedge: \mid>1-1 \vee \wedge$.

ґ . Laidler JK. "Reaction kinetics", ' st ed, Vol. 1, 19v•; $: 9,7 r, 7 \varepsilon$.

r. Dhaneshwar SS, Gairola N, Kandpal M, Bhatt L, et al. Synthesis, kinetic studies and pharmacological evaluation of mutual azo prodrug of ${ }^{\circ}$-aminosalicylic acid with D-phenylalanine for colon specific delivery in inflammatory bowel disease. Bioorganic and Medicinal Chemistry Letters r... $v ; 1 v: 119 v_{-} 19 \cdot r$.
Iv. Block HJ, Beale MJ. " Wilson and Gisvold's Textbook of organic medicinal and pharmaceutical chemistry ", 11th ed., (r... $),$ p: rvo.

1^. Younes $Z$, Johnson DA. New developments and concepts in antimicrobial therapy for intra-abdominal infections. Cur Gastroentero Rep $r \ldots ; r$ : rVY-rAr.

19. Bussemer T, Otto I, Bodmeier R. Pulsatile drug-delivery systems. Crit Rev Ther Drug Carrier Syst $r \ldots 1 ; 1 \wedge: \leqslant r r-\leqslant 0 \wedge$.

$r \cdot$ Basit AW. Advances in colonic drug delivery. Drugs $r \ldots 0 ; 70: 1991-r \ldots V$.

r). Mooter GV, Kinget R. Oral colon-specific drug delivery. Drug Deliv $1990 ; r: \wedge 1-94$.

$r$ r. Ashford M, Fell JT. Targeting drugs to the colon: delivery systems for oral administration. J Drug Target $199 \leqslant ; Y: Y \leqslant 1-$ YOA.

$r$ r. Friend DR. New oral delivery systems for treatment of inflammatory bowel disease. Adv Drug Del Rev r...0;0V:r $\leqslant V-r$ ro.

r $\varepsilon$. Chourasia MK, Jain SK. Pharmaceutical approaches to colon targeted drug delivery systems. J Pharm Sci r...r;т.זr_ז.

r. Jain A, Gupta Y, Jain S. Perspectives of biodegradable natural polysaccharides for site-specific drug delivery to the colon. J Pharm Sci $r \ldots v ; 1 \cdot:$ A $_{-} \mid r \wedge$.

rr. Rubin R, Swartz M. Trimethoprim and sulfamethoxazole. New Engl J Med $191 \cdot ; r \cdot r: \varepsilon r \tau-\varepsilon r r$

rr. Roujeau J, Kelly J, Naldi L. Medication use and the risk of Stevens-Johnson syndrome or toxic epidermal necrolysis. New Engl J Med 1990;rrr:17..-17.V.

$r \varepsilon$. Dhaneshwar SS, Nagpal D, Vodhankar SL, Rathi B, Kadam SS. Synthesis, kinetic studies and pharmacological evaluation of mutual azo prodrug of $\bullet$-aminosalicylic acid for colon-specific drug delivery in inflammatory bowel disease. European Journal of Medicinal Chemistry r... $\vee \leqslant$; $: \wedge \wedge 0_{-} \wedge 9$.

ro. Vogel AI, " Textbook of practical organic chemistry ", rrd ed., (197r), p:091. 
Irq J Pharm

Vol. ${ }^{9} \& 1 \cdot$, No. ${ }^{\prime}$,

$r \cdot 1$.

$\underline{r \cdot 1 \cdot \text { Mosul College of Pharmacy }}$ 